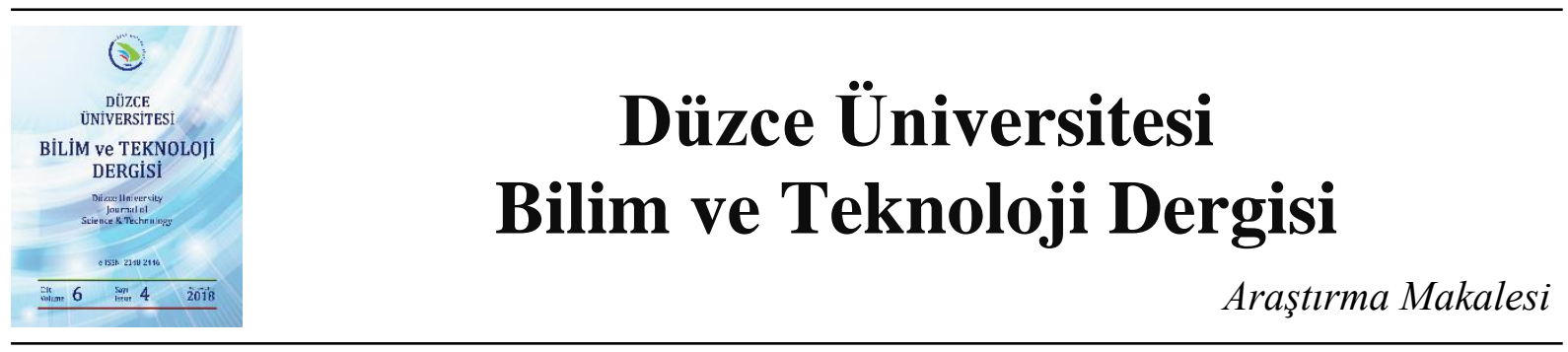

\section{Yongalevha Üretiminde Hammadde Kaynaklarının Optimizasyonu ve Teknolojik Yönden İncelenmesi}

\author{
Cengiz GÜLER ${ }^{\mathrm{a}, *}$, Murat İBiş ${ }^{\mathrm{b}}$ \\ ${ }^{a}$ Orman Endüstri Mühendisliği Bölümü, Orman Fakültesi, Düzce Üniversitesi, Düzce, TÜRKiYE \\ ${ }^{b}$ Orman End. Müh., Kastamonu Entegre Ağaç Sanayi Tic. A.Ş., Gebze, TÜRKIYE \\ *Sorumlu yazarin e-posta adresi: cengizguler@duzce.edu.tr
}

\begin{abstract}
ÖZET
Günümüzde yongalevha üretiminde \% 50'ye yakın yurt dışı kaynaklı özellikle ABD'den getirilen çam yongası kullanılmaktadır. Bu çalışmada dışa bağımlılığı azaltmak amacıyla mevcut kaynaklarımızdan endüstriyel atıklardan elde edilen kapak türü malzemelerin alternatif hammadde olarak kullanılabilirliği araştırılmıştır. $\mathrm{Bu}$ amaçla tüm levha gruplarında meşe $\% 15$, kavak $\% 5$ ve talaş $\% 10$ oranında sabit tutularak ithal çam yongası $\%$ $70,65,55,50,45$ ve 40, kapak tahtası sirasıyla, \% 0, 5, 10, 15, 20, 25 oranlarında kullanılarak fabrikasyon ortamında üretimler gerçekleştirilmiştir. Levhaların üretiminde yapıştırıcı olarak üre formaldehit, sertleștirici olarak amonyum sülfat ve hidrofobik madde olarak parafin kullanılmıştır. Her bir grup levhadan örnekler elde edilerek fiziksel özelliklerden, yoğunluk, su alma (SA) ve kalınlık artımı (KA), mekanik özelliklerden eğilme direnci (ED), elastikiyet modülü (EM), yüzeye dik çekme direnci (YDÇD) ve vida tutma direnci (VTD) standartlara uygun olarak incelenmiştir. Buna göre ithal yolla temin edilen hazır çam yongasının yongalevha üretimde kullanımı azaltılarak bunun yerine aynı üretim koşullarında kapak tahtasının levha üretimde değerlendirilmesinin teknolojik olarak standartlara uygun olduğu görülmüştür.
\end{abstract}

Anahtar Kelimeler: Kapak tahtası, Fiziksel ve mekanik özellikler, Hammadde, İthal çam, Yongalevha.

\section{Investigation Technological Properties and Optimization of Raw Material Sources in Particleboard Production}

\begin{abstract}
Todays pine chips are obtained from the USA. It has been used in the production of particleboard. In order to reduce external dependence, the availability of cover type material obtained from industrial wastes from our existing sources as an alternative raw material was investigated. For this purpose, different production combinations have been produced particleboards in the factory; while the ratios of oak $15 \%$, poplar $5 \%$ and sawdust $10 \%$ kept constant; ratios of the imported pine chips $\% 70,65,55,50,45,40$ and industrial wastes $\% 0$, $5,10,15,20,25$ have been used respectively. Urea formaldehyde as adhesive, ammonium sulphate as hardener and paraffin as hydrophobic material were used in the production of particleboards. By obtaining samples from each group of boards, the physical properties (density, water uptake and thickness swelling) and mechanical
\end{abstract}


properties (bending strength, elasticity, perpendicular to the surface tensile strength and screw holding strength) were investigated in accordance with the standards. According to this, it has been observed that it is technologically possible to produce wood base panels by replacing imported wood chips with industrial wood chips under the same production conditions.

Key Words: Side board, physical and mechanical properties, raw materials, imported pine, particleboard.

\section{GiRIS}

Orman ürünleri sektöründe, gelişen sanayi kollarından biride yongalevha endüstrisidir. Bu endüstride orman ve kereste fabrikası artıklarının değerlendirilmesinin yanı sıra tüm lifli lignoselülozik kaynaklar hammadde olarak kullanılabilmektedir. Fabrikada lignoselülozik materyaller çok çeşitlilik arz etmektedir. Her türlü odunsu materyalin kullanılabilmesinden dolayı yurt içinden ve yurt dışından temin edilen kaynaklar değerlendirilmektedir [1].

Çeşitli hammadde kaynaklarından ülkemizde çok sayıda çalışma yapılmıştır. Akbulut [2] yurt içinden özellikle orman kaynaklarımızdan temin edilen çeşitli hammadde ve endüstriyel odunlardan, ORUSVezirköprü yongalevha fabrikasında üretilen $18 \mathrm{~mm}$ kalınlığındaki levhaların teknolojik özelliklerini incelemiş olup sonuçta standartlara uygun olduğunu belirtmiştir.

Kalaycıŏglu [3] yapmış olduğu bir çalışmada yerli sahil çamı odunlarının yongalevha üretiminde kullanılabilirliği konusunda laboratuvar şartlarında gerçekleştirip, deneme levhalarının üretimi için Sinop bölgesinden alınan 20, 10 yaş grubu gövde ve dal odunlarını kullanmıştır. Sonuç olarak sahil çamı odunlarından elde edilen yongalevhalarda, kalınlık artımı ve su alma miktarları tüm levha grupları için yüksek bulunmuştur. Parafin kullanım oranının $\% 0,5$ 'ten $\% 1$ 'e çıkarılması ile bu özellikler iyileştirilebileceği gibi, fabrikalarda uygulanan yongaların $200-300{ }^{\circ} \mathrm{C}$ gibi yüksek sıcaklıkta kurutulması ile levhalarda geriye yaylanma ve buna bağlı olarak kalınlık artımı ve su alma miktarlarında bir azalma olacağı kanaatine varıldığı belirlenmiştir.

Akyıldız [4] yapmış olduğu çalışmada, Türkiye'deki yongalevha ve liflevha endüstrisinde faaliyet gösteren işyerlerinin sayısı, üretim kapasitesi, kapasite kullanım oranı, üretim, dış ticaret, istihdam, yatırım değerleri belirlenerek her iki sektör için ayrı incelenmiştir. Sektörün sorunları irdelenerek çözümler önerilmiştir. Ürün özelliklerinin kullanıcılar tarafından yeterince bilinmemesi sorunlar yaşanmasına neden olmakta olduğu sonucuna varmıştır.

Bir çalışmada çam kontrplak atıklarından üretilen yongalevhaların bazı teknolojik özellikleri incelenmiştir. $\mathrm{Bu}$ amaçla çam kontrplak atıklarından ve çam odunundan elde edilen yongalar farklı oranlarda $(\% 25, \% 50, \% 75, \% 100)$ karıştırılarak yongalevhalar üretilmiştir. Sonuçta üretilen yongalevhaların mekanik ve fiziksel özellikleri tüm gruplar için EN'nin ilgili standartlarında genel kullanım amaçlı yongalevhalar için öngörülen değerleri karşıladığını belirtmişlerdir [5].

Motorlu testere talaşının yongalevha üretimine uygunluğu araştırılmıştır. Çalışmada hammadde olarak sahil çamı, kayın ve dişbudak odunlarından elde edilen motorlu testere talaşı ile endüstriyel odun yongaları kullanılmıştır. Elde edilen levhaların fiziksel ve mekanik özellikleri standart yongalevha 
özellikleriyle karşılaştırılarak mortorlu testere talaşının yongalevha üretimine uygunluğu belirlenmiştir. Elde edilen sonuçlar değerlendirildiğinde fiziksel ve mekanik özelliklerin genel amaçl1 kullanımlar için gerekli özellikleri sağladığı görülmüştür [6].

Sevinçli [7] yapmış olduğu çalışmasında laboratuvar şartlarında farklı karışım oranlarına sahip (\% 0 , $25,50,100)$ atık lavanta bitkisi ve kızılçam yongalarından, bağlayıcı olarak kullanılan üre formaldehit tutkalının değişen oranlarına göre $0.65 \mathrm{gr} / \mathrm{cm}^{3}$ yoğunluklu yongalevhalar üretmiştir. Sonuç olarak, $0.65 \mathrm{gr} / \mathrm{cm}^{3}$ yoğunlukta, belirlenen karışım ve tutkal oranlarına göre standartlara uygun bir levhanın üretilebileceği ortaya koymuştur.

Durmuş [8] yapmış olduğu çalışmada, odunsu hammaddelerden elde edilen yongalevha orman ürünleri sanayi alanında çok geniş bir kullanım alanına sahip olduğunu belirtmiştir. Hammadde alanında yaşanan problemler işletmeleri alternatif hammadde tedarikine sevk etmiştir. Yongalevha talebini etkileyebilecek faktörler; levha tüketim miktarı, fiyatı, ithalat ve ihracat miktarları, toplam ülke nüfusu, mobilya üretim miktarı, ikame malların fiyatı gibi faktörleri bu çalışmada kullanmıştır. Ayrıca odun kökenli atıkların levha endüstrisinde yeniden kullanım imkanları üzerine yapılan başka bir çalışmada kullanılmış odun ve odun kökenli ürünlerin geri dönüşümünün optimum çözüm olacağı vurgulanmıştır [9].

Orman kaynaklarından elde edilen odun hammaddesinin üstünlüklerinin çok fazla olması ve yeni teknolojik gelişmelerle birlikte kullanım alanlarının her geçen gün artması orman alanlarından sağlanacak odun hammaddesinin miktarı üzerinde bir baskı oluşturduğu özellikle belirtilmiştir. Masif ağaç malzeme yerine odun kökenli levhaların kullanılması, ağaç malzemenin yeniden kullanılması, atıklarının değerlendirilmesi ve odunsu atıklardan enerji üretilmesi gibi geleneksel ve teknolojik alternatif yöntemler geliştirilmiştir. $\mathrm{Bu}$ nedenle, özellikle orman endüstri işletmelerinin odunsu atıklarının değerlendirilmesi büyük önem kazanmıştır [10].

Ülkemizde OCAK/2013 itibariyle 28 yongalevha tesisi (22'si faal) ve 18'i faal lif levha tesisi üretimlerini sürdürmektedir. Son yıllarda eklenen yeni kapasiteler doğrultusunda dünyada söz sahibi bir kapasite ve üretim teknolojisine ulaşmıştır. Yıllık olarak 6 milyon $\mathrm{m}^{3}$ yongalevha, 5 milyon $\mathrm{m}^{3}$ lif levha üretim kapasitemiz bulunmaktadır. Ülkemizin yıllık üretim miktarı ise (Yonga+Lif Levha) 7,5 8 milyon $\mathrm{m}^{3}$ civarındadır [7].

Birçok kaynaklarda belirtildiği üzere orman ürünleri sektörünün en önemli problemlerden biri hammadde teminindeki güçlükler olduğu vurgulanmaktadır. Lif ve yongalevha sanayinin toplam hammaddeye olan ihtiyaç 13 milyon $\mathrm{m}^{3}$ (18.500.000ster/yıl) civarındadır. Atıl vaziyette bulunan tesislerimizle birlikte Kurulu kapasitemizin toplam hammadde ihtiyacı ise 18 milyon $\mathrm{m}^{3}=24.000 .000$ ster/y1l = 12.000.000ton/y1l kadardır [11].

Hammadde ihtiyacının yaklaşı $\%$ 65'i yurt içi geri kalan \% 35'i ithal yolla temin edilmektedir. Yonga ve lif-levha sektöründe 2018 yılı Orman Genel Müdürlüğü ile lif ve yonga üreten firmalar arasında lif yonga odunu temin ve tahsisli satış konusunda protokol imzalanarak orman kaynaklarımızdan temin edilecek lif yonga odunu miktarı 7.500.000 ster olarak belirlenmiştir [12].

Bununla beraber ithal yoluyla elde edilen yongalar maliyeti yüksek ve dolayısıyla levha üretim maliyetlerinin de artmasına neden olmaktadır. Dışa bağımlılığı azaltacak yöntemler geliştirilerek mevcut kaynaklarımızı ithal çam yongası ile birlikte rantabl olarak değerlendirmek bir zorunluluktur. 
$\mathrm{Bu}$ çalışmada ithal edilen hazır yonganın üretimde kullanımı azaltılarak bunun yerine aynı üretim koşullarında kapak tahtası ve benzeri endüstriyel atıkların üretimde değerlendirilmesi yoluna gidilecektir. Hammadde kullanım oranlarına bağlı olarak kısıtlı kaynakların en verimli ve en az kayıp ile kullanımı planlamak bu çalışmanın en öncelikli hedefidir.

$\mathrm{Bu}$ çalışmada fabrikasyon ortamında gerçekleştirilmiş olan her bir varyasyonda rastgele deney levhaları seçilecek levhaların teknolojik özellikleri TS-EN 312 [13] standardına uygunluğu yönünden incelenmiştir.

\section{MATERYAL Ve METOD}

Deneme levhaları Kastamonu Entegre Ağaç Sanayi-Gebze fabrikası ortamında sürekli-sonsuz preste üretilmiştir. $\mathrm{Bu}$ çalışmada $\mathrm{ABD}$ menşeli çam yongası ile kapak yongaları değişik oranlarda kullanılarak levha üretimleri gerçekleştirilmiştir.

Deneme levhalarının üretiminde; \%15 meşe yongas1, \%5 kavak yongası, \%10 şerit testere talaşı ve değişik oranlarda ABD menşeli hazır çam yongası ile kapak tahtası yongaları kullanılmıştır. Deneme levhalarının üretim planı Tablo 1'de verilmiştir.

Tablo 1. Yongalevha üretiminde kullanılan odun hammaddesi oranları.

\begin{tabular}{ccccccc}
\hline GRUP & MEŞE & KAVAK & ÇAM ODUNU & KAPAK & TALAŞ & TOPLAM \\
\hline A & 15 & 5 & 70 & 0 & 10 & 100 \\
\hline B & 15 & 5 & 65 & 5 & 10 & 100 \\
\hline C & 15 & 5 & 60 & 10 & 10 & 100 \\
\hline D & 15 & 5 & 55 & 15 & 10 & 100 \\
\hline E & 15 & 5 & 50 & 20 & 10 & 100 \\
\hline F & 15 & 5 & 45 & 25 & 10 & 100 \\
\hline
\end{tabular}

Orta tabaka (OT) ve Dış tabaka (DT) için kullanılan tutkalın iyi bir yapışma sağlaması için mümkün olduğunca üniform boyutta küçük taneciklere ayrılması sağlandı. Böylece bütün yonga/talaş yüzeylerinin tutkalla temas etmesi sağlanmıştır. Bunu gerçekleştirmek için hava üflemeli tutkal taneciklerini küçük parçacıklara ayıran enjektörlerden faydalanmıştır. Tam kuru yonga ağırlığına oranla orta tabakada \% 7, dış tabakalarda ise \% 11 tutkal kullanılmıştır. Tablo 2'de görüldüğü gibi OT ve DT'da kullanılan tutkal reçetesi farklılık göstermiştir. OT'de sıcak preste iyi bir sertleşme sağlanması için tam kuru yonga ağırlığına oranla daha fazla sertleştirici (\% 2.8), DT yongalarının sıcak pres öncesi sertleşme olmaması için daha az sertleştirici (\% 1.8) kullanılmıştır.

Parafin hidrofobik bir maddedir. Levhaların kalınlık artışı ve su alma miktarını azaltmak için kullanılmaktadır. Bu çalışmada tam kuru yonga ağırlığına oranla \% 0.3 oranında kullanılmıştır. Parafin mumları $\mathrm{C}_{\mathrm{n}} \mathrm{H}_{2 \mathrm{n}+2}$ formülünde hidrokarbonlardır. $50-100^{\circ} \mathrm{C}$ arasında erime dereceleri mevcuttur. Tablo 3’te parafinin analiz değerleri verilmiştir. 
Tablo 2. Üre formaldehit tutkall.

\begin{tabular}{lcc}
\hline \multicolumn{1}{c}{ Özellikler } & Orta Tabaka & Dış Tabakalar \\
\hline Katı madde oranı (\%) & 62 & 57 \\
\hline Viskozite (cps) & 280 & 75 \\
\hline Akma zamanı $(\mathrm{sn})$ & 60 & 18 \\
\hline $\mathrm{pH}$ & $8.3-8.5$ & $8.3-8.5$ \\
\hline Yoğunluk $\left(\mathrm{kg} / \mathrm{m}^{3}\right)$ & 1270 & 1250 \\
\hline Serbest formaldehit oranı (\%) & 0.14 & 0.077 \\
\hline Jell time $(\mathrm{sn})$ & $44-45$ & - \\
\hline Depolama süresi (gün) & 90 & 90 \\
\hline
\end{tabular}

Tablo 3. Parafinin analiz değerleri.

\begin{tabular}{ll}
\hline \multicolumn{1}{c}{ Özellikler } \\
\hline Fiziksel Görünüşü & Beyaz süt (emülsiyon) \\
\hline Koku & Hafif parafinik koku \\
\hline Suda Çözünürlük & Dağılabilir \\
\hline Katı Madde oranı $(\%)$ & 60 \\
\hline Özgül Ağırlık $\left(\mathrm{gr} / \mathrm{cm}^{3}\right)(200 \mathrm{C})$ & 0.96 \\
\hline pH & $9-10$ \\
\hline Viskozite $(\mathrm{sn})$ & $13-23$ \\
\hline
\end{tabular}

Levhalar fabrikasyon ortamında üretildikten sonra TS 642 [14]'ye göre sıcaklığı $20 \pm 2{ }^{\circ} \mathrm{C}$ ve bağıl nemi $\% 65 \pm 5$ olan iklimlendirme odasına alınmıştır.

Her gruptan rastgele üretilen levhalardan ilgili standartlara göre örnekler alınmış ve her bir mekanik test için altışar adet deney örneği hazırlanmıştır. Daha sonra fiziksel özelliklerinden yoğunluk (TS-EN 323) [15], kalınlık artımı ve su alma (TS-EN 317) [16], mekanik özelliklerden; eğilme direnci, eğilmede elastikiyet modülü (TS-EN 310) [17] ve yüzeye dik yönde çekme direnci (TS-EN 319) [18], vida tutma direnci (TS-EN 320) [19] üniversal test cihazı kullanılarak tespit edilmiştir. Numune alma işlemi TS-EN 326-1 [20] standardına göre yapılmıştır. Deney örneklerinin kalınlık ve uzunluklarının tespitinde $0.01 \mathrm{~mm}$ hassasiyetteki dijital kumpas kullanılmıştır. Elde edilen sonuçlar ile SPSS istatistik analizleri yapılmıştır.

\section{BULGULAR VE TARTISMMA}

Üç tabakalı olarak üretilen yongalevhaların yoğunluk, kalınlık artımı, su alma yüzdeleri, eğilme direnci, eğilmede elastikiyet modülleri ve yüzeye dik çekme ve vida tutma dirençlerine ait ortama değerler ile Duncan testi sonuçları Tablo 4'te gösterilmiştir.

Levha yoğunluğu en yüksek A grubu levhalarda $0.636 \mathrm{~g} / \mathrm{cm}^{3}$, en düşük $\mathrm{D}$ grubu levhalarda 0.621 $\mathrm{g} / \mathrm{cm}^{3}$ olarak bulunmuş olup istatistik anlamda yalnız A grubu levhalarda önemli bir fark çıkmıştır. 
TS-EN 312 [13]'ye göre levhadaki ortalama yoğunluğa dair tolerans $\pm \% 10$ olabilir denilmektedir. Ancak levha içerisinde ortalama yoğunluk dağılımı oldukça homojen olup standartlara uygundur.

Tablo 4. Tabakalı olarak üretilen yongalevhaların bazı teknolojik özellikleri.

\begin{tabular}{ccccccc}
\hline Levha tipi & $\mathrm{A}$ & $\mathrm{B}$ & $\mathrm{C}$ & $\mathrm{D}$ & $\mathrm{E}$ & $\mathrm{F}$ \\
\hline Yoğunluk $\left(\mathrm{g} / \mathrm{cm}^{3}\right)$ & $0.636 \mathrm{a}$ & $0.624 \mathrm{~b}$ & $0.622 \mathrm{~b}$ & $0.621 \mathrm{~b}$ & $0.624 \mathrm{~b}$ & $0.625 \mathrm{~b}$ \\
& $(0.01)$ & $(0.11)$ & $(0.16)$ & $(0.11)$ & $(0.13)$ & $(0.11)$ \\
Kalınlık artımı 2h & $4.17 \mathrm{a}$ & $4.21 \mathrm{a}$ & $4.69 \mathrm{a}$ & $4.69 \mathrm{a}$ & $6.71 \mathrm{~b}$ & $7.73 \mathrm{~b}$ \\
$(\%)$ & $(1.54)$ & $(1.84)$ & $(1.37)$ & $(1.52)$ & $(1.99)$ & $(1.62)$ \\
Kalınlık artımı 24h & $17.17 \mathrm{a}$ & $16.24 \mathrm{a}$ & $18.24 \mathrm{ab}$ & $16.51 \mathrm{~b}$ & $20.08 \mathrm{c}$ & $19.63 \mathrm{c}$ \\
$(\%)$ & $(1.86)$ & $(2.12)$ & $(1.39)$ & $(1.38)$ & $(0.85)$ & $(1.03)$ \\
Su Alma 2 h & $32.20 \mathrm{a}$ & $30.33 \mathrm{~b}$ & $24.21 \mathrm{~b}$ & $30.42 \mathrm{bc}$ & $37.33 \mathrm{c}$ & $38.35 \mathrm{c}$ \\
$(\%)$ & $(5.30)$ & $(7.03)$ & $(2.70)$ & $(6.41)$ & $(6.31)$ & $(6.16)$ \\
Su Alma 24 h (\%) & $68.22 \mathrm{a}$ & $63.00 \mathrm{a}$ & $64.09 \mathrm{a}$ & $62.68 \mathrm{ab}$ & $72.97 \mathrm{~b}$ & $76.50 \mathrm{c}$ \\
& $(6.17)$ & $(8.24)$ & $(5.22)$ & $(7.93)$ & $(5.25)$ & $(5.16)$ \\
Eğilme direnci (N/mm $\left.{ }^{2}\right)$ & $14.52 \mathrm{a}$ & $12.09 \mathrm{a}$ & $12.69 \mathrm{a}$ & $12.23 \mathrm{a}$ & $12.94 \mathrm{a}$ & $12.65 \mathrm{a}$ \\
& $(1.86)$ & $(1.50)$ & $(2.12)$ & $(2.12)$ & $(1.92)$ & $(2.01)$ \\
Elastikiyet Modülü & $2657.63 \mathrm{a}$ & $2389.39 \mathrm{a}$ & $2465.38 \mathrm{a}$ & $2444.02 \mathrm{a}$ & $2464.39 \mathrm{a}$ & $2416.01 \mathrm{a}$ \\
$\left(\mathrm{N} / \mathrm{mm}^{2}\right)$ & $(264.31)$ & $(295.16)$ & $(336.59)$ & $(227.67)$ & $(270.17)$ & $(333.58)$ \\
Yüzeye Dik Çekme direnci & $0.411 \mathrm{ab}$ & $0.436 \mathrm{~b}$ & $0.398 \mathrm{ab}$ & $0.400 \mathrm{ab}$ & $0.355 \mathrm{a}$ & $0.383 \mathrm{ab}$ \\
$\left(\mathrm{N} / \mathrm{mm}^{2}\right)$ & $(0.08)$ & $(0.02)$ & $(0.03)$ & $(0.06)$ & $(0.04)$ & $(0.05)$ \\
Vida tutma direnci Yüzey & $1083.33 \mathrm{a}$ & $1071.33 \mathrm{a}$ & $1040.00 \mathrm{a}$ & $1142.66 \mathrm{a}$ & $1053.33 \mathrm{a}$ & $1050.33 \mathrm{a}$ \\
$(\mathrm{N})$ & $(116.68)$ & $(39.82)$ & $(144.66)$ & $(47.72)$ & $(55.42)$ & $(147.57)$ \\
Vida tutma direnci Yan (N) & $689.66 \mathrm{a}$ & $726.00 \mathrm{a}$ & $694.00 \mathrm{a}$ & $714.00 \mathrm{a}$ & $670.66 \mathrm{a}$ & $774.00 \mathrm{a}$ \\
& $(46.87)$ & $(103.11)$ & $(120.12)$ & $(39.50)$ & $(15.04)$ & $(38.19)$ \\
\hline & & & & & &
\end{tabular}

Kalınlık artımı 2 saat suda bekletme sonucunda en yüksek F grubu levhalarda (\% 7.73), en düşük A grubu levhalarda (\% 4.17) olarak gerçekleşmiştir. 24 saat suda bekletme sonucunda ise en yüksek E grubu levhalarda (\% 20.08), en düşük B grubu levhalarda (\%16.24) olarak gerçekleşmiştir. TS-EN 312 [13] tip P3'te nemli şartlarda kullanılan yük taşıyıcı olmayan levhalar için 24 saattte en fazla \% 14 olması gerektiği belirtilmiştir. Buna göre kalınlık artımı 24 saat için standart değerden tüm gruplarda yüksek bulunmuştur. Diğer yandan ithal çam odunu yongası oranı arttıkça kalınlık artımında kısmı bir artış olduğu ifade edilebilir. Yapılan varyans analizi sonuçlarında ise levha grupları arasında fark önemli çıkmıştır. Su alma miktarı tutkal türü ve sertleştirici türüne bağlı olarak değişiklik gösterebilir. 2 saat suda bekletme sonucunda en yüksek F grubu levhalarda (\% 38.35), en düşük B grubu levhalarda (\%30.33) olarak tespit edilmiştir. 24 saat suda bekletme sonucunda en yüksek F grubu levhalarda (\% 76.50) en düşük D grubu levhalarda (\% 62.68) olarak tespit edilmiştir. Su alma miktarı ile ilgili standartlarda herhangi bir bilgi yoktur. Su alma miktarı levhalar arasında istatistik anlamda önemli çıkmış olup hammadde kullanım oranına bağlı olarak değişiklik göstermiştir. Eğilme direnci en yüksek A grubu levhalarda $14.52 \mathrm{~N} / \mathrm{mm}^{2}$, en düşük B grubu levhalarda $12.09 \mathrm{~N} / \mathrm{mm}^{2}$ olarak tespit edilmiştir. Farklı kalınlıklarda üretilmiş yongalevhaların teknolojik özelliklerinin incelendiği bir çalışmada $18 \mathrm{~mm}$ kalınlıktaki levhalar için $14 \mathrm{~N} / \mathrm{mm}^{2}$ bulunmuştur [21]. Eğilme direncini en çok levha yoğunluğu etkilemektedir. Levha yoğunluğu arttıkça eğilme mukavemeti artar. Ancak hammadde gereksinimini de artar. Bu nedenle optimal eğilme direncine sahip levha üretiminin gerçekleştirilmesi ana hedeftir. Yongalevhaların eğilme direnci kullanım yerine göre değişiklik gösterir. Kuru şartlarda iç donanımlarda (mobilya dahil) kullanılan levhalar (Tip P2) genel özellikleri TS EN 312 [13]'de 
belirtilmiştir. Burada eğilme direnci $13 \mathrm{~mm}$ den büyük $20 \mathrm{~mm}$ ye kadar olan levhalar için en az 11 $\mathrm{N} / \mathrm{mm}^{2}$ olarak belirtilmiştir. Genel olarak bütün levha grupları buna uygundur. İstatistik anlamda da eğilme direncinde levha grupları arasındaki fark önemli çıkmamıştır ( $p>0,05)$. Yani ithal çam yongasının azaltılmasıyla veya kapak tahtası kullanım oranının artırılması ile eğilme direncinde önemli bir değişim meydana gelmemiştir.

Elastikiyet modülü, Eğilme direncine paralel olarak en yüksek A grubu levhalarda $2657 \mathrm{~N} / \mathrm{mm}^{2}$, en düşük B grubu levhalarda $2389 \mathrm{~N} / \mathrm{mm}^{2}$ olarak tespit edilmiştir. Kuru şartlarda iç donanımlarda (mobilya dahil) kullanılan levhalar (Tip P2) genel özellikleri TS EN 312 [13]'de belirtilmiştir . Burada elastikiyet modülü $13 \mathrm{~mm}$ den büyük $20 \mathrm{~mm}$ ye kadar olan levhalar için en az $1600 \mathrm{~N} / \mathrm{mm}^{2}$ olarak belirtilmiştir. Bu durumda elastikiyet modülü değerleri genel olarak standartlara uygun bulunmuştur. Elastikiyet modülü değerleri bakımından gruplar arasında istatistiksel olarak önemli bir fark bulunmamıştır ( $\mathrm{p}>0,05$; Tablo 5-6).

Yüzeye dik çekme direnci (YDÇD) en yüksek B grubu levhalarda $0.43 \mathrm{~N} / \mathrm{mm}^{2}$ en düşük $\mathrm{E}$ grubu levhalarda $0.35 \mathrm{~N} / \mathrm{mm}^{2}$ olarak bulunmuştur. Yapılan varyans analizi sonuçlarına göre ortalamalar arasında önemli bir fark ortaya çıkmıştır. Kuru şartlarda iç donanımlarda (mobilya dahil) kullanılan levhalar (Tip P2) genel özellikleri TS EN 312 [13] de belirtilmiştir. Burada yüzeye dik çekme direnci (iç yapışma) $13 \mathrm{~mm}$ den büyük $20 \mathrm{~mm}$ ye kadar olan levhalar için en az $0.35 \mathrm{~N} / \mathrm{mm}^{2}$ olarak belirtilmiştir. Buna göre tüm gruplarda yüzeye dik çekme direnci değerleri standartlara uygundur. Bir çalışmada $18 \mathrm{~mm}$ kalınlıktaki levhalar için $0.34 \mathrm{~N} / \mathrm{mm}^{2}$ bulunmuştur [21].

Tablo 5. Deneme levhalarının fiziksel ve mekanik özelliklerine ait basit varyans analiz sonuçları

\begin{tabular}{|c|c|c|c|c|c|c|}
\hline & Varyans Kaynakları & $\begin{array}{l}\text { Toplam } \\
\text { Kareler }\end{array}$ & S.D. & $\begin{array}{c}\text { Ortalama } \\
\text { Kareler }\end{array}$ & $\begin{array}{c}\text { F- } \\
\text { Oran1 }\end{array}$ & $\begin{array}{l}\text { Önem } \\
\text { Düzeyi }\end{array}$ \\
\hline \multirow{3}{*}{ 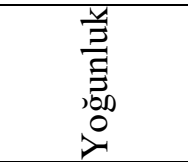 } & Gruplar arası & 3049.960 & 5 & 609.992 & 3.973 & 0.002 \\
\hline & Gruplar içi & 17502.547 & 114 & 153.531 & & \\
\hline & Toplam & 20552.507 & 119 & & & \\
\hline \multirow{3}{*}{ 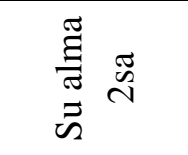 } & Gruplar aras1 & 1345.939 & 5 & 269.188 & 7.912 & 0.000 \\
\hline & Gruplar içi & 1837.278 & 54 & 34.024 & & \\
\hline & Toplam & 3183.217 & 59 & & & \\
\hline \multirow{3}{*}{ 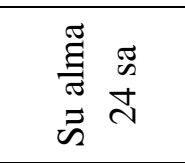 } & Gruplar aras1 & 1654.559 & 5 & 330.912 & 7.919 & 0.000 \\
\hline & Gruplar içi & 2256.586 & 54 & 41.789 & & \\
\hline & Toplam & 3911.145 & 59 & & & \\
\hline \multirow{3}{*}{ 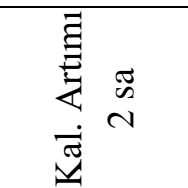 } & Gruplar aras1 & 110.784 & 5 & 22.157 & 8.002 & 0.000 \\
\hline & Gruplar içi & 149.517 & 54 & 2.769 & & \\
\hline & Toplam & 260.300 & 59 & & & \\
\hline \multirow{3}{*}{ 无志艺 } & Gruplar aras1 & 131.283 & 5 & 26.257 & 13.585 & 0.000 \\
\hline & Gruplar içi & 104,371 & 54 & 1.933 & & \\
\hline & Toplam & 235.654 & 59 & & & \\
\hline \multirow{3}{*}{ 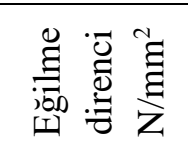 } & Gruplar aras1 & 23.023 & 5 & 4.605 & 1.226 & 0.322 \\
\hline & Gruplar içi & 112.702 & 30 & 3.757 & & \\
\hline & Toplam & 135.725 & 35 & & & \\
\hline \multirow{2}{*}{ 灾 } & Gruplar aras1 & 271794.889 & 5 & 54358.978 & 0.644 & 0.668 \\
\hline & Gruplar içi & 2531957.409 & 30 & 84398.580 & & \\
\hline
\end{tabular}




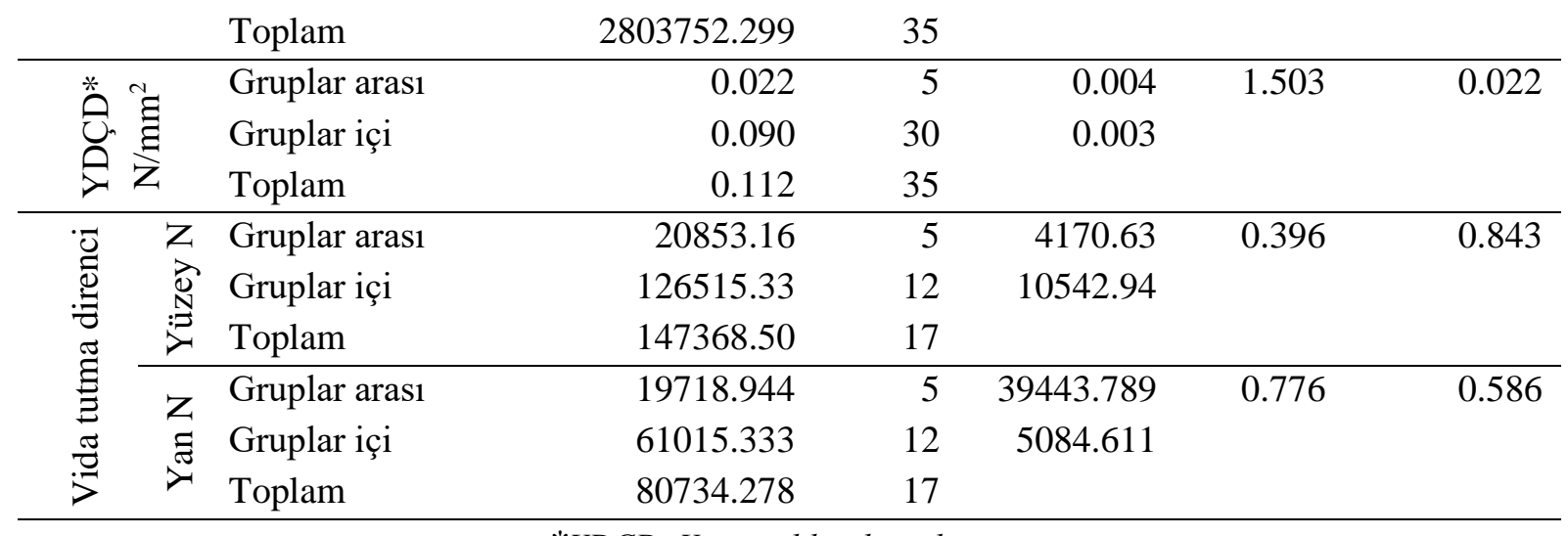

*YDÇD: Yüzeye dik çekme direnci.

Yongalevhaların fiziksel ve mekanik özelliklerine ait varyans analizi test sonuçları Tablo 5'te verilmiştir. Üretilmiş yongalevha gruplarında, her iki yöndeki VTD değerleri bakımından aralarında istatistiksel olarak fark yoktur ( $p>0,05)$. Vida tutma direnci yüzey ve yan olarak belirlenmiş olup yüzeyde 1040-1083 N, yan 670-774 N arasında değişmektedir. Ayçiçeği saplarından üretilen levhalarda, levha kenarına dik vida tutma direnci 419.7-521.9 $\mathrm{N}$, yüzeye dik vida tutma direnci ise 447.5-751.1 N arasında yer almıştır [22]. Melamin kaplı yongalevhalarda yan vida tutma direnci 907 $\mathrm{N}$, yüzeye dik vida tutma direnci $1230 \mathrm{~N}$ olarak belirlenmiştir [23]

\section{SONUC}

Bu çalışmada dışa bağımlılığı azaltmak amacıyla mevcut kaynaklarımızdan endüstriyel atıklardan elde edilen kapak türü malzemelerin alternatif hammadde olarak kullanılabilirliği araştırılmıştır. Fabrikasyon ortamında ithal çam ve endüstriyel kapak tahtası yongaları belirli oranlarda karıştırılarak üretimi gerçekleştirilen levhaların tamamı 24 saat için kalınlık artımı miktarı hariç standartlara uygun bulunmuştur. Özellikle mekanik özelliklerde ithal çam yongası oranı artırılması ile önemli bir değişme meydana gelmemiştir. Buna göre ithal yolla temin edilen hazır çam yongasının yongalevha üretimde kullanımı azaltılarak bunun yerine aynı üretim koşullarında kapak tahtasının levha üretimde değerlendirilmesinin teknolojik olarak standartlara uygun olup buna göre yurt içinden temin edilen kapak tahtalarının \% 25 oranına kadar rahat bir şekilde kullanılabileceğini göstermiştir.

Yurt dışından getirilen yongalar daha homojen yapıda olduğundan dolayı levhanın direnç özelliklerinde homojen bir yapı oluşturduğu söylenebilir. Ancak kapak tahtası gibi endüstriyel atıkların piyasadan yeterince temin edilebildiği takdirde yongalevha üretiminde ithal çam yongasına alternatif olarak kullanılabileceği ifade edilebilir.

\section{$\underline{\text { V. KAYNAKLAR }}$}

[1] C. Güler, S. Sancar, "Yongalevha Fabrikasının Çalışma Prensibi ve Farklı Presleme Tekniğinin Levha Kalitesi Üzerine Etkisi,” Düzce Üniversitesi, Ormancılık Dergisi, c. 12, s.1, ss. 110, 2015. 
[2] T. Akbulut, “Orus-Vezirköprü Yongalevha Fabrikasında Üretilen Levhaların Teknolojik Özellikleri,” Yüksek Lisans Tezi, Orman Endüstri Müh. Böl., İstanbul Üniversitesi, İstanbul, 1991.

[3] H. Kalaycığlu, "Sahil Çamı (Pinus pinaster) Odunlarının Yongalevha Üretiminde Kullanılması İmkanları,” Doktora Tezi, Orman Endüstri Müh. Böl., Karadeniz Teknik Üniversitesi, Trabzon, 1991.

[4] M. H. Akyıldız, "Türkiye'de Yongalevha ve Lif Levha Endüstrisinin Yapısı ve Sorunları," Doktora Tezi, Fen Bilimleri Enstitüsü, Gazi Üniversitesi, Ankara, 2003.

[5] S. Çolak, H. Öztürk, A. Demir, C. Demirkır, "Yongalevha Üretiminde Kontrplak Atıklarının Kullanılması,” Selçuk Üniversitesi, Selçuk Teknik Dergisi, Özel Say1-1, ss. 601-612, 2015.

[6] S. Çelik, "Motorlu Testere Talaşının Yongalevha Üretiminde Değerlendirilmesi, Yüksek Lisans Tezi, Fen Bilimleri Enstitüsü, Bartın Üniversitesi, Bartın, 2017.

[7] Y. Sevinçli, "Atık Lavanta Bitkisinden Üretilen Yongalevhanın Mekanik ve Fiziksel Özelliklerinin İncelenmesi," Yüksek Lisans Tezi, Fen Bilimleri Enstitüsü, Süleyman Demirel Üniversitesi, Isparta, 2014.

[8] M. T. Durmuş, “Türkiye'de Yongalevha Endüstrisinde Talep Tahmini,” Yüksek Lisans Tezi, Fen Bilimleri Enstitüsü, Karadeniz Üniversitesi, Trabzon, 2002.

[9] C. Demirkır, S. Çolak, "Odun Kökenli Atıkların Levha Endüstrisinde Yeniden Kullanım İmkanları” Kafkas Üniversitesi, Artvin Orman Fakültesi Dergisi, c. 7, s. 1, ss. 41-50, 2006.

[10] T. Türkoğlu, E. Baysal, M. E. Ergün, H. Toker, M. Yüksel, A. Özçifçi "Orman Ürünleri İşletmelerinde Odunsu Atık Yönetimi Uygulamalarının Değerlendirilmesi," Selçuk Üniversitesi, Selçuk Teknik Dergisi, Özel Sayı-1, 2015, ss. 517-529.

[11] S. Dayaniklioğlu, "Türkiye'de Yonga ve Lif Levha Sektörü” Mobilya Dekorasyon Dergisi, s. 117, ss. 52-60, 2013.

[12] Anonim, (2018), "Yongalevha Üreten Firmalar arasında 2018 y1l1 Lif Yonga Odunu Temin ve Tahsisli Satışına Dair Protokolü,” [Online] Erişim : www.ogm.gov.tr.

[13] TS EN 312, "Yongalevhalar-Özellikler," TSE Ankara, 2012.

[14] TS 642, "Kondisyonlama ve/veya Deney İçin Standard Atmosferler-Özellikler," TSE Ankara, 1997.

[15] T EN 323, “Ahşap Esaslı Levhalar-Birim Hacim Ağırlı̆̆ının Tayini,” TSE Ankara, 1999.

[16] TS EN 317, "Yongalevhalar ve Lif Levhalar-Su İçerisine Daldırma İşleminden Sonra Kalınlığına Şişme Tayini,” TSE Ankara, 1999.

[17] TS EN 310, "Ahşap Esaslı Levhalar-Eğilme Dayanımı ve Eğilme Elastikiyet Modülünün Tayini," TSE, Ankara, 1999. 
[18] TS EN 319, "Yongalevhalar ve Lif Levhalar-Levha Yüzeyine Dik Çekme Dayanımının Tayini,” TSE, Ankara, 1999.

[19] TS EN 320, "Yongalevhalar ve Lif Levhalar-Vida Tutma Mukavemetinin Tayini," TSE, Ankara, 2011.

[20] TS EN 326-1, “Ahşap Esaslı Levhalar-Numune Alma Kesme ve Muayene Bölüm 1:Deney Numunelerinin Seçimi, Kesimi ve Deney Sonuçlarının Gösterilmesi,” TSE, Ankara, 1999.

[21] C. Güler, "Farklı Kalınlıklarda Üretilmiş Yongalevhaların Bazı Teknolojik Özellikleri,” Düzce Üniversitesi, Ormanc1lık dergisi, c. 11, s.1, ss. 52-63, 2015.

[22] İ. Bektaş, C. Güler, H. Kalaycıŏlu, "Ayçiçeği (Helianthus annuus L.) Saplarından ÜreFormaldehit Tutkalı ile Yongalevha Üretimi," KSÜ Fen ve Mühendislik Dergisi, c. 5, s. 2, ss. 49-56, 2002.

[23] B. C. Bal, E. Akçakaya, Z. Gündeş, "Screw-Holdıng Capacıty of Melamıne-Faced Fıberboard And Particleboard Used In Furniture Production," Mugla Journal of Science and Technology c. 2, ss. $49-52,2016$ 